\title{
Oral contraceptives and hypertension in women: results of the enrolment phase of Tabari Cohort Study
}

\author{
Mahdi Afshari ${ }^{1}$, Reza Alizadeh-Navaei ${ }^{2}$ and Mahmood Moosazadeh ${ }^{2^{*}}$
}

\begin{abstract}
Background: The association between oral contraceptives (OCP) and hypertension has been reported in the literature with controversial results. According to the growing use of OCPs among women in Iran, this study aims to investigate the association between the duration of the OCP consumption and risk of hypertension among Iranian women.

Methods: In the current study, the data collected during the enrolment phase of the Tabari cohort were analyzed. Of 6106 women recruited in the cohort, 133 pregnant women were excluded. Epidemiological variables were collected using pre-designed questionnaires as well as the health insurance evidences. In addition, blood pressure and anthropometric factors were measured based on the standard guidelines. Chi square and partial correlation tests as well as logistic regression models were applied for data analysis.

Results: Frequency of oral contraceptive use among 35-70 year-old women in Tabari cohort study (TCS) was 42.2\% (2520/5973). Hypertension was observed among 25\% (1793/5973) of them. The adjusted odds ratio for OCP use was 1.23 (95\% confidence interval: $1.08,1.40, p=0.002$ ). The corresponding odds ratios for $61-120$ months and more than 120 months OCP use were $1.39(1.12,1.73)$ and $1.47(1.16,1.87)$ respectively.
\end{abstract}

Conclusions: Oral contraceptives especially in long term use can be associated with hypertension.

Keywords: Blood pressure, Oral contraceptive, Systole, Diastole

\section{Background}

Non-communicable disease such as cardiovascular problems are main causes of death worldwide responsible for approximately half of the burden of diseases especially in low-middle income countries [1, 2]. Hypertension is the most common cause of the cardiovascular diseases as well as chronic kidney disorders and heart failure in worldwide. Hypertension is also responsible for at least $45 \%$ of the cardiovascular related mortality and $51 \%$ of deaths following stroke. About one billion adults are suffering from hypertension in the world and it is predicted

\footnotetext{
*Correspondence: mmoosazadeh1351@gmail.com

${ }^{2}$ Gastrointestinal Cancer Research Center, Non-communicable Diseases

Institute, Mazandaran University of Medical Sciences, Sari, Iran

Full list of author information is available at the end of the article
}

to be increased to 1.5 billion until 2025. Many hypertensive cases remain undiagnosed without treatment. Therefore, sudden deaths and early mortality due to the consequences of hypertension are considerable [3-5]. The role of hypertension in mortality among women is higher than that of the other preventable cardiovascular risk factors [6].

Results of a meta-analysis reported the prevalence of hypertension among the Iranian population aged over 15 as of $20.4 \%(16.5,24.2)$ [7]. The prevalence of this disorder among the Tabari cohort population was estimated as of $22.2 \%(2281 / 10,255)$ for all population, $24.9 \%$ (1523/6106) for women and $18.3 \%$ (758/4149) for men [8]. Another meta-analysis reported that Iranian women had hypertension about $1.3 \%$ higher than Iranian men. 
The latter study, suggested the OCP use as one of the reasons for higher rates of hypertension among women [9].

Several evidences have introduced OCPs as one of the probable risk factors of the hypertension $[6,10,11]$. Kim and Park found that women used OCP more than 24 months, had 1.96 folds higher risk of hypertension compared to those never used OCP [6]. OCP use has getting increased worldwide especially in the recent years [12]. During the foundation of the family planning council from 1967, the use of oral contraceptives was initiated in Iran [13]. Contraceptive methods have significant role in reducing the problems following unintended pregnancy and abortion [14].

Among different methods of contraception, OCP use is more common because of various factors such as reversibility, lower side effects, high affectivity and also its role in reducing risk of dysmenorrhea, endometrial and ovarian cancers and ovarian cysts [15].

On the other hand, oral contraceptives may increase the risk of different disorders such as obesity, vomiting/ nausea, vertigo, anxiety and depression [16, 17]. Due to the wide use of the OCPs among women during the fertility age, the attributed risk of these drugs is expected to be considerable. In the study conducted by Barikani and Saeedi among 328 Iranian women over 30, prevalence of hypertension was reported as of $32 \%, 8.8 \%$ of them experienced OCP use for $9.8 \pm 6.1$ years. However, they did not find any significant correlation between OCP use and hypertension [18]. In addition, oral contraceptives are widely used in Iran so that $24 \%$ of women in the capital city Tehran reported history of modern methods of contraception including OCPs [19].

As mentioned above, hypertension plays a critical role in the pathogenesis of non-communicable diseases. Although OCP is considered as one of the probable risk factors of the hypertension, controversies in the available literature due to various factors such as sample characteristics and study designs needs more investigations in different populations. The present study aims to investigate the association between $\mathrm{OCP}$ use and hypertension using the dose-response effect of oral contraceptives in the Tabari cohort population.

\section{Methods}

The present study is a cross sectional (descriptive-analytic) research. Required information were obtained from the registered data of the enrolment phase of the Tabari population-based cohort. This cohort is a part of national cohort titled "Prospective Epidemiological Research Studies in IrAN (PERSIAN)" [20, 21]. More details of the cohort has been explained elsewhere [8].

The enrolment phase of the TABARI cohort has been established between 2015 and 2017. The study samples were selected by census method. Of 10,255 samples from the urban and mountainous areas of Sari district (capital of Mazandaran province in north of Iran), 6016 were women aged between 35 and 70 years. Some trained health volunteers in the urban areas as well as health staffs in the mountainous areas invited these participants based on the lists extracted from the health records.

The information were collected using standard questionnaires $[8,20,21]$, physical examination and blood sampling. Before the study, the cohort staff of the Tabari study were trained and achieved the relevant qualification.

Some of the variables of the standard questionnaire required for the present study were age, height, weight, waist circumference, socioeconomic status, residence area, educational level, number of the previous pregnancies, menopausal status, familial history of hypertension, breast feeding duration, OCP use and its duration, history of hypertension and diabetes mellitus and using antihypertensive/anti-diabetic drugs, systolic/diastolic blood pressure, blood sugar, TG, TC, HDL and MET (metabolic equivalent of task).

OCP use was defined as at least one month consumption of the oral contraceptives during the fertility period until the questioning time in the enrolment phase of the cohort. Those reporting a history of the OCP use were also asked regarding the duration of the OCP consumption.

The participants' blood pressure as well as anthropometric variables were measured according to PERSIAN cohort protocol. Blood samples were collected after $12 \mathrm{~h}$ fasting. Fasting blood glucose, TG and HDL were measured using Auto Analyzer, BT 1500 (Biotechnica, Italy). $\mathrm{CBC}$ was also measured using Alpha cell counter (Nihon Kohden, Tokyo, Japan).

Hypertension was defined when systolic blood pressure was $\geq 140 \mathrm{mmHg}$ or diastolic pressure was $\geq 90 \mathrm{mmHg}$ or participants reported previous history of hypertension. Physical activity of the participants was measured using a standard questionnaire calculating a MET score as a unit for activity.

SPSS version 24 was used for statistical analyses. All data were described as percent frequency, mean and standard deviation. Comparing the grouping variables between the participants with and without OCP use was performed using Chi square test. Independent $\mathrm{T}$ test was applied for comparison of the OCP use duration between these two groups. The association between hypertension and OCP use was assessed using logistic regression models. The adjusted models were run by stepwise method in seven models. To investigate the role of the OCP use duration, 1-11 months, 12-24 months, 25-60 months, 60-120 months and more than 120 months use were 
compared with "never use" group. Mean arterial pressure (MAP) was calculated using $(2 * \mathrm{DBP}+\mathrm{SBP}) / 3$ formula [22]. Spearman correlation and partial correlation coefficients were estimated to assess the crude and adjusted correlation between blood pressure and the duration of the OCP use. Due to the high correlation coefficient between the number of pregnancies and duration of breastfeeding, just the "number of pregnancies" variable was entered into the multivariate models.

\section{Results}

Of 6106 women registered in the Tabari cohort, 133 pregnant women were excluded. Of the 5973 remaining study subjects, 17.93 (25\%) had hypertension. Mean systolic, diastolic and MAP (mean arterial pressure) of the study subjects were $73.0 \pm 7.7,114.2 \pm 13.7$ and $86.8 \pm 9.2$ respectively.

History of OCP use was observed in 42.2\% (2520/5973) of the present cohort population. Moreover, frequency of using oral contraceptives for 1-11 months, 12-24 months, 61-120 months and more than 120 months were 239 (4\%), 640 (10.7\%), 655 (11\%), 549 (9.2\%) and 437 (7.3\%) respectively. Mean (SD) of OCP use among 2520 pregnant women reporting consumption of these drugs was 69.9 (65.8).

The epidemiological characteristics of the participants with and without OCP use has been shown in Table 1 . Women with history of OCP use compare to those without had higher rate of obesity $(45.5 \%$ vs. $40.4 \%$ respectively, $p<0.001)$, abdominal obesity $(74.2 \%$ vs. $66.5 \%$ respectively, $p<0.001)$ and diabetes mellitus $(20.8 \%$ vs. $16.4 \%$ respectively, $p<0.001$ ).

Frequency of hypertension among OCP users was higher than that among women without history of OCP use $(28.5 \%$ vs. $22.4 \%$ respectively, $p<0.001$; OR $=1.38$, $05 \%$ CI 1.22, 1.51). The crude and adjusted ORs based on different models has been presented in Table 2. The odds ratio for hypertension controlling for age was estimated as of $1.33(1.18,1.51)$. Corresponding figure adjusting for age, BMI, waist circumference, parity and co-morbidity with diabetes mellitus was $1.23(1.08,1.40, p=0.002)$.

Frequencies of hypertension among women without history of OCP use, OCP use for 1-11 months, 12-24 months, 25-60 months, 61-120 months and more than 120 months were $22.4 \%, 24.7 \%, 28.1 \%, 28.4 \%, 30.1$ and $29.3 \%$ respectively $(p<0.001)$. Considering the OCP non-users as reference group, the adjusted odds ratios for 61-120 months and more than 120 months OCP use were estimated as of $1.39(1.12,1.73)$ and $1.47(1.16,1.87)$ respectively (Table 3 ).

Table 4 shows that mean DBP, SBP and MAP were higher among women with OCP use compared to those without $(p<0.001)$. According to the results of partial correlation and controlling the effect of potential confounders, positive correlations were observed between the duration of the OCP use and the mean blood pressures.

Also, among the 2520 study participants with history of OCP use, prevalence of Obesity, overweight and normal BMI was $45.5 \%, 40.6$ and $13.8 \%$ respectively. Of them, $74.2 \%$ had high waist circumference $(\geq 88 \mathrm{~cm})$ (Table 1$)$.

Prevalence of hypertension in women with obesity, overweight and normal BMI was 30.6\%, 23 and 15.8\% respectively $(p<0.001)$. In addition, prevalence of hypertension in women with abdominal obesity was significantly higher than that among women with normal waist circumference $(29.5 \%$ vs. $14.6 \%$ respectively, $p<0.001)$.

\section{Discussion}

The present study investigated the association between OCP use and hypertension among the TABARI cohort population. Our results showed that after adjustment of the effect of potential confounders, prevalence of hypertension among women with history of OCP use was $23 \%$ higher than that among those without OCP use. In addition, women used OCP for 61-120 months as well as those with OCP use more than 120 months had significantly 39 and $47 \%$ higher chance of developing hypertension compared to those without experience of OCP use. Moreover, duration of the OCP use was directly correlated with mean systolic, diastolic and arterial pressures.

Park et al. investigated the association between OCP use and hypertension among South Korean women aged 35-55 in 2013. Although using oral contraceptives for more than 24 months caused approximately two folds increase in the risk of developing hypertension, they did not find any significant risk of disease for less than two years OCP use [6]. Such dose response effect of OCP was similar to that observed in the current study.

According to the results of a meta-analysis conducted in 2017 by Liu et al., highest doses of OCP compared to the lowest doses caused approximately 50\% higher risk of developing hypertension. They also showed the corresponding relative risks for Asian, North American, developed and developing countries as of $2.12(1.15,3.91), 1.32$ $(1.10,1.59), 1.26(1.09,1.45)$ and $2.13(1.06,4.27)$ respectively. That meta-analysis showed $13 \%$ increase in the risk of hypertension per each 5 years higher OCP use [11]. These evidences are in parallel with the findings of our study.

According to the Wang study results, Chinese women with OCP use had approximately $40 \%$ higher chance of developing hypertension compared to those without OCP use [22].

Another study in Chinese women showed the significant role of cumulative use of oral contraceptives so that 
Table 1 Epidemiological characteristics of female participants of TCS

\begin{tabular}{|c|c|c|c|c|}
\hline \multicolumn{2}{|c|}{ Variables (epidemiological characteristics) } & \multicolumn{2}{|c|}{ Oral contraceptive use } & \multirow{3}{*}{$\begin{array}{l}p \text { value (Chi square } \\
\text { or Independent } T \\
\text { test) }\end{array}$} \\
\hline & & \multirow{2}{*}{$\begin{array}{l}\text { Yes }(n=2520) \\
13.0\end{array}$} & \multirow{2}{*}{$\begin{array}{l}\text { No }(n=3453) \\
19.2\end{array}$} & \\
\hline Age group & $35-39$ & & & \\
\hline & $40-49$ & 36.7 & 34.5 & \\
\hline & $50-59$ & 33.2 & 28.9 & \\
\hline & $60-70$ & 17.1 & 17.4 & \\
\hline BMI & $<25$ & 13.8 & 20.0 & $<0.001$ \\
\hline & $25-29.9$ & 40.6 & 39.6 & \\
\hline & $\geq 30$ & 45.5 & 40.4 & \\
\hline WC & $<88$ & 25.8 & 33.5 & $<0.001$ \\
\hline & $\geq 88$ & 74.2 & 66.5 & \\
\hline Social economic level & 1 & 22.6 & 23.1 & 0.011 \\
\hline & 2 & 21.2 & 20.1 & \\
\hline & 3 & 21.2 & 19.6 & \\
\hline & 4 & 19.4 & 18.2 & \\
\hline & 5 & 15.6 & 18.9 & \\
\hline residence area & Urban & 63.5 & 69.0 & $<0.001$ \\
\hline & Mountainous & 36.5 & 31.0 & \\
\hline Educational level & University/college & 12.6 & 20.2 & $<0.001$ \\
\hline & $9-12$ years in school & 24.2 & 26.7 & \\
\hline & $6-8$ years in school & 11.4 & 9.2 & \\
\hline & $1-5$ years in school & 31.8 & 24.2 & \\
\hline & No schooling & 20.0 & 19.7 & \\
\hline Parity & $<2$ & 3.0 & 13.6 & $<0.001$ \\
\hline & $2-3$ & 45.1 & 43.1 & \\
\hline & $4-5$ & 31.7 & 20.2 & \\
\hline & $>5$ & 20.2 & 23.1 & \\
\hline Menopause & No & 52.1 & 56.8 & $<0.001$ \\
\hline & Yes & 47.9 & 43.2 & \\
\hline $\mathrm{HDL}$ & $\geq 50$ & 60.0 & 58.4 & 0.230 \\
\hline & $<50$ & 40.0 & 41.6 & \\
\hline TG & $<150$ & 61.0 & 62.2 & 0.314 \\
\hline & $\geq 150$ & 39.0 & 37.8 & \\
\hline TC & $<200$ & 59.6 & 61.5 & 0.148 \\
\hline & $\geq 200$ & 40.4 & 38.5 & \\
\hline Met & $<$ Median & 47.3 & 54.0 & $<0.001$ \\
\hline & $\geq$ Median & 52.7 & 46.0 & \\
\hline Diabetes & No & 79.2 & 83.6 & $<0.001$ \\
\hline & Yes & 20.8 & 16.4 & \\
\hline Family history of hypertension & No & 41.9 & 42.8 & 0.482 \\
\hline & Yes & 58.1 & 57.2 & \\
\hline Breastfeeding, mean $\pm S D$; mon & & $66.2 \pm 39.4$ & $59.9 \pm 41.7$ & $<0.001$ \\
\hline
\end{tabular}

using OCP more than 15 years caused about 50\% higher risk of developing hypertension [10].

In contrast to the above results, OCP use did not have any significant effect on developing hypertension among women living in the other parts of Iran [18]. In addition, Farahmand et al. found that OCP use less than 36 months did not have significant association with cardiometabolic parameters [23]. There is no evidence of the effect of geographical areas and ethnicity on the association between OCP use and hypertension. Therefore, the observed differences between the results of the current study and the similar researches in other parts of Iran might be due to 
Table 2 Crude and adjusted associations (logistic regression) between hypertensive and oral contraceptive use

\begin{tabular}{|c|c|c|c|c|}
\hline \multirow[t]{2}{*}{ Variables } & \multirow[t]{2}{*}{ Model } & \multicolumn{3}{|c|}{ Oral contraceptive use; OR $(95 \% \mathrm{Cl})$} \\
\hline & & No & Yes & $p$ value \\
\hline \multirow[t]{7}{*}{ Has hypertensive } & Crud & Ref & $1.38(1.22-1.55)$ & $<0.001$ \\
\hline & Adjusted for age & Ref & $1.33(1.18-1.51)$ & $<0.001$ \\
\hline & Adjusted for Social economic, Education level, area resident & Ref & $1.32(1.17-1.49)$ & $<0.001$ \\
\hline & Adjusted for BMI, WC, Met & Ref & $1.30(1.16-1.47)$ & $<0.001$ \\
\hline & Adjusted for TG, TC, HDL-C, DM & Ref & $1.32(1.17-1.49)$ & $<0.001$ \\
\hline & Adjusted for pregnancy number, Menopause & Ref & $1.28(1.13-1.45$ & $<0.011$ \\
\hline & Adjusted for age, BMI, WC, pregnancy number, DM & Ref & $1.23(1.08-1.40)$ & 0.002 \\
\hline
\end{tabular}

Table 3 Crude and adjusted associations (logistic regression) between hypertension and duration of oral contraceptive use

\begin{tabular}{|c|c|c|c|c|c|c|c|}
\hline \multirow[t]{2}{*}{ Variables } & \multirow[t]{2}{*}{ Model } & \multicolumn{6}{|c|}{ Duration of oral contraceptive use (month); OR (95\% CI) } \\
\hline & & Never & $1-11$ & $12-24$ & $25-60$ & $61-120$ & $>120$ \\
\hline \multirow[t]{2}{*}{ Hypertension } & Crude & Ref & $1.13(0.83-1.54)$ & $1.35(1.12-1.63)$ & $1.37(1.14-1.65)$ & $1.48(1.22-1.81)$ & $1.43(1.15-1.78)$ \\
\hline & $\begin{array}{l}\text { Adjusted age, BMI, WC, } \\
\text { pregnancy number, DM }\end{array}$ & Ref & $1.28(0.92-1.79)$ & $1.05(0.86-1.30)$ & $1.15(0.93-1.40)$ & $1.39(1.12-1.73)$ & $1.47(1.16-1.87)$ \\
\hline
\end{tabular}

Table 4 Crude and adjusted correlation coefficients between DBP, SBP and MAP with duration of oral contraceptive use

\begin{tabular}{|c|c|c|c|c|c|c|}
\hline \multirow[t]{3}{*}{ Variables } & \multicolumn{2}{|c|}{ oral contraceptive use, Mean and $95 \%$ confidence interval } & \multicolumn{4}{|c|}{ Correlation with duration of oral contraceptive use } \\
\hline & \multirow[t]{2}{*}{ No } & \multirow[t]{2}{*}{ Yes } & \multicolumn{2}{|c|}{ Pearson correlation coefficient } & \multicolumn{2}{|c|}{$\begin{array}{l}\text { Partial correlation } \\
\text { coefficient* }\end{array}$} \\
\hline & & & $r$ & $p$ value & $\mathrm{r}$ & $p$ value \\
\hline DBP & $72.6(72.4-72.9)$ & $73.6(73.3-73.9)$ & 0.07 & $<0.001$ & 0.05 & $<0.001$ \\
\hline SBP & $113.3(112.8-113.7)$ & $115.5(115.0-116.1)$ & 0.07 & $<0.001$ & 0.05 & $<0.001$ \\
\hline MAP & $86.2(85.9-86.5)$ & $87.6(87.2-87.9)$ & 0.07 & $<0.001$ & 0.06 & $<0.001$ \\
\hline
\end{tabular}

*Adjusted by age, BMI, WC, pregnancy number, DM, Met

the other factors such as methodology and the characteristics of the study subjects. Similarly, OCP use and its duration did not play any role in developing hypertension among Australian women [24].

The most of the recent literatures have provided significant evidences regarding the positive effect of OCP use on developing hypertension. Ribeiro et al. reported the role of the estrogen component of the oral contraceptive pills on activation of the rennin angiotensin system leading to elevated blood pressure even in the lower doses [25]. Similarly, Takao Saruta reported an increased level of plasma rennin in the hypertensive patients using oral contraceptives [26]. However, some other studies did not agree with this mechanism. Other mechanisms such as the effect of progesterone, fluid retention by estrogen, renal abnormal function due to sodium-lithium countertransport and intra-renal vascular lesions [12]. It should be noted that the exact mechanism is necessary to be investigated by further studies. Such effect can be stronger in combination with other risk factors such as age, family history of hypertension, renal diseases and obesity at least 6 months after beginning the OCP use. Usually antihypertensive treatment is needed especially during the mild and reversible hypertensions without adverse consequences [6].

One of the strengths of the present study is the observed highly force of association indicating higher chance of hypertension. The second strength of our study is the observed dose-response association between OCP use and hypertension which is in keeping with the Hill criteria for causal association [27]. Although cross sectional studies have no enough power to prove the causal relationships because of the lack of temporal time relationships between the exposure and outcome, such evidence can be in favor of the role of OCP use in having more chance of hypertension among 
women. In addition, the repeatability of our results with the most similar evidences which is of great importance in the epidemiology and causal inference.

One of the main limitations of our study is lack of enough evidence regarding the temporal relationship between the exposure (OCP) and outcome (hypertension) of interest. The data supporting the results have been obtained cross-sectional from the first phase of the TCS. Therefore re-call bias due to remembering the exact time of OCP use and the first episode of the hypertension is expected. However, it seems that re-call bias will be low in use of methods such as contraception. Moreover, the health records of the Iranian health centers used as the main source of the baseline information is reliable leading to the low risk of systematic error.

\section{Conclusions}

Our study showed higher rates of hypertension among women with the history of OCP use. We also found a considerable direct effect of the duration of contraception with pills. Future longitudinal studies focusing on temporal relationship between OCP use and hypertension, beside the observed dose-response effects, can provide more credible evidences to introduce oral contraceptives as independent risk factors for developing hypertension.

\section{Abbreviations \\ TCS: Tabari Cohort Study; OCP: oral contraceptive; DM: diabetes mellitus; BMI: body mass index; WC: waist circumference; MET: metabolic equivalent of task; TG: triglycerides; TC: total cholesterol; HDL-C: high density lipoprotein; DBP: diastolic blood pressure; SBP: systolic blood pressure; MAP: mean arterial pres- sure; CBC: complete blood count; OR: odds ratio.}

\section{Acknowledgements}

We would like to thank all the members of PERSIAN cohort study (Ministry of Health and Medical Education and Mazandaran University of Medical Sciences).

\section{Authors' contributions \\ MM and MA acquired data, performed the statistical analyses, interpreted data, and drafted and revised the manuscript for important intellectual content and approved the final version. RA interpreted data, reviewed the analyses and approved the final version. All authors have read and approved the manuscript.}

\section{Funding}

This study was supported by research deputy of Mazandaran University of Medical Science (grant No. 2524) and Iranian Ministry of Health (grant No. 700/534). The funding body played no role in the design of the study and collection, analysis, and interpretation of data and in writing or decision to publish this manuscript.

\section{Availability of data and materials}

The datasets used and/or analysed during the current study are available from the corresponding author on reasonable request.

\section{Declarations}

\section{Ethics approval and consent to participate}

TCS was confirmed by Mazandaran University of Medical science ethical committee (IR.MAZUMS. REC.1395.2524).All ethical principles of the Helsinki ethical declaration have been met and written informed consent were obtained from all the participants.

\section{Consent for publication}

Not applicable.

\section{Conflict of interest}

The authors declare that they have no Competing interests.

\section{Author details}

${ }^{1}$ Pediatric Gastroenterology and Hepatology Research Center, Zabol University of Medical Sciences, Zabol, Iran. ${ }^{2}$ Gastrointestinal Cancer Research Center, Non-communicable Diseases Institute, Mazandaran University of Medical Sciences, Sari, Iran.

Received: 25 December 2020 Accepted: 25 May 2021

Published online: 28 May 2021

\section{References}

1. Abegunde DO, Mathers CD, Adam T, Ortegon M, Strong K: The burden and costs of chronic diseases in low-income and middle-income countries. Lancet 2007, 370(9603):1929-1938.

2. Esteghamati A, Meysamie A, Khalilzadeh O, Rashidi A, Haghazali M, Asgari F, et al. Third national Surveillance of Risk Factors of Non-Communicable Diseases (SuRFNCD-2007) in Iran: methods and results on prevalence of diabetes, hypertension, obesity, central obesity, and dyslipidemia. BMC Public Health. 2009;9:167.

3. Simo LP, Agbor VN, Noubiap JJN, et al. Hypertension prevalence, associated factors, treatment and control in rural Cameroon: a cross-sectional study. BMJ Open 2020;10:e040981.

4. Nahimana MR, Nyandwi A, Muhimpundu MA, Olu O, Condo JU, Rusanganwa A, et al. A population-based national estimate of the prevalence and risk factors associated with hypertension in Rwanda: implications for prevention and control. BMC Public Health. 2017;18(1):2.

5. Nascimento BR, Brant LCC, Yadgir S, Oliveira GMM, Roth G, Glenn SD,et al. Trends in prevalence, mortality, and morbidity associated with high systolic blood pressure in Brazil from 1990 to 2017: estimates from the "Global Burden of Disease 2017" (GBD 2017) study. Popul Health Metr. 2020;18(Suppl 1):17.

6. Park H, Kim K. Associations between oral contraceptive use and risks of hypertension and prehypertension in a cross-sectional study of Korean women. BMC Womens Health. 2013;13:39.

7. Afsargharehbagh R, Rezaie-Keikhaie K, Rafiemanesh H, Balouchi A, Bouya S, Dehghan B. Hypertension and pre-hypertension among Iranian adults population: a meta-analysis of prevalence, awareness, treatment, and control. Curr Hypertens Rep. 2019;21(4):27

8. Kheradmand M, Moosazadeh M, Saeedi M, Poustchi H, Eghtesad S, Esmaeili R, et al. Tabari Cohort profile and preliminary results in urban areas and mountainous regions of Mazandaran, Iran. Arch Iran Med. 2019;22(6):279-85.

9. Haghdoost AA, Sadeghirad B, Rezazadehkermani M. Epidemiology and heterogeneity of hypertension in Iran: a systematic review. Arch Iran Med. 2008;11(4):444-52.

10. Wei W, Li Y, Chen F, Chen C, Sun T, Sun Z, et al. Dyslipidaemia, combined oral contraceptives use and their interaction on the risk of hypertension in Chinese women. J Hum Hypertens. 2011;25(6):364-71.

11. Liu H, Yao J, Wang W, Zhang D. Association between duration of oral contraceptive use and risk of hypertension: a meta-analysis. J Clin Hypertens. 2017;19:1032-41.

12. Woods JW. Oral contraceptives and hypertension. Hypertension. 1988;11(3 Pt 2):I111-5.

13. Aghajanian A. Family planning and contraceptive use in Iran, 1967-1992. Int Family Plan Perspect. 1994;20(2):66-9. 
14. AsadiSarvestaniKh, LengKhoo S, MalinaMalek N, Mat Yasin S, Ahmadi A. Comparison of the Determinant Factors of Using the Contraceptive Methods between Rural and Urban Women in Shiraz County, Iran. Journal of Midwifery and Reproductive Health. 2017; 5(4): 1041-1052.

15. Azima S, Mousavi S. Oral contraceptive pills use and hypertension. Int J Pharm Sci Invent. 2017;6(1):47-9.

16. Shulman LP. The state of hormonal contraception today: benefits and risks of hormonal contraceptives: combined estrogen and progestin contraceptives. Am J Obstet Gynecol. 2011;205(4):S9-S13.

17. Grossman D, Fernández L, Hopkins K, Amastae J, Potter JE. Perceptions of the safety of oral contraceptives among a predominantly Latina population in Texas. Contraception. 2010;81(3):254-60.

18. Barikani A, Saeedi F. Prevalence of hypertension in women above 30 years of age in Minoudar, Qazvin, Iran. ARYA Atheroscler J. 2012; 8(special issue in national hypertension treatment): S158-62.

19. Sadat-Hashemi SM, Ghorbani R, Majdabadi HA, Farahani FK. Factors associated with contraceptive use in Tehran, Iran. Eur J Contracept Reprod Health Care. 2007:12(2):148-53.

20. Poustchi H, Eghtesad S, Kamangar F, Etemadi A, Keshtkar AA, Hekmatdoost A, et al. Prospective epidemiological research studies in Iran (the PERSIAN Cohort Study): rationale, objectives, and design. Am J Epidemiol. 2018;187(4):647-55.

21. Eghtesad S, Mohammadi Z, Shayanrad A, Faramarzi E, Joukar F, Hamzeh B, et al. The PERSIAN cohort: providing the evidence needed for healthcare reform. Arch Iran Med. 2017;20(11):691-5.
22. Wang C, Li Y, Bai J, Qian W, Zhou J, Sun Z, Ba L, Wei W, Li H, Sun T. General and central obesity, combined oral contraceptive use and hypertension in Chinese women. Am J Hypertens. 2011;24(12):1324-30.

23. Farahmand M, Ramezani Tehrani F, Rostami Dovom M, Hashemi S, Azizi F. The impact of oral contraceptives on cardiometabolic parameters. J Endocrinol Invest. 2016;39(3):277-83.

24. Chiu CL, Lind JM. Past oral contraceptive use and self-reported high blood pressure in postmenopausal women. BMC Public Health. 2015;15:54.

25. Ribeiro CCM, Shimo AKK, Lopes MHBM, Lamas JLT. Effects of different hormonal contraceptives in women's blood pressure values. Rev Bras Enferm. 2018;71(suppl 3):1453-1459.

26. Saruta T, Saade GA, Kaplan NM. A possible mechanism for hypertension induced by oral contraceptives. Diminished feedback suppression of renin release. Arch Intern Med. 1970;126(4):621-6.

27. Fedak KM, Bernal A, Capshaw ZA, Gross S. Applying the Bradford Hill criteria in the 21st century: how data integration has changed causal inference in molecular epidemiology. Emerg Themes Epidemiol. 2015;12:14

\section{Publisher's Note}

Springer Nature remains neutral with regard to jurisdictional claims in published maps and institutional affiliations.
Ready to submit your research? Choose BMC and benefit from:

- fast, convenient online submission

- thorough peer review by experienced researchers in your field

- rapid publication on acceptance

- support for research data, including large and complex data types

- gold Open Access which fosters wider collaboration and increased citations

- maximum visibility for your research: over $100 \mathrm{M}$ website views per year

At BMC, research is always in progress.

Learn more biomedcentral.com/submissions 